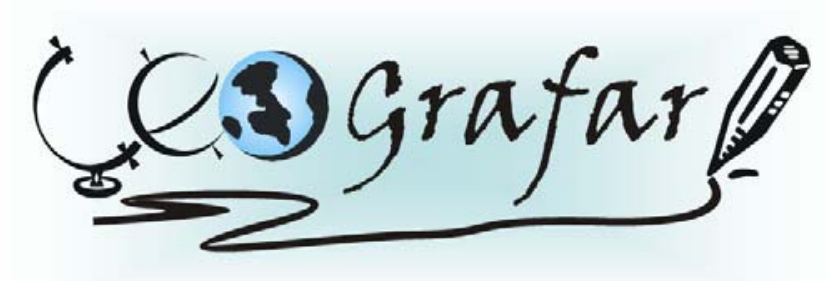

Revista Eletrônica do Programa de Pós-Graduação em Geografla - UFPR

\title{
POLUIÇÃO HÍDRICA POR DEJETOS DE SUÍNOS: UM ESTUDO DE CASO NA ÁREA RURAL DO MUNICÍPIO DE QUILOMBO, SANTA CATARINA ${ }^{1}$
}

\author{
FABIOLA ORO ASSIS ${ }^{2}$, ANA MARIA MURATORI ${ }^{3}$
}

\begin{abstract}
RESUMO
A atividade suinícola, essencial para a economia de muitos municípios do oeste catarinense, tem contribuído para o desencadeamento de problemas ambientais, marcadamente, em relação aos recursos hídricos. Os principais resíduos resultantes dessa atividade, os dejetos, podem ser caracterizados como poluidores de grande magnitude. Nesse sentido, $\mathrm{O}$ presente estudo procurou avaliar a qualidade da água em uma área de atividade suinícola, localizada na área rural do município de Quilombo, oeste de Santa Catarina, A pesquisa teve como base a abordagem sistêmica, permitindo a análise dos distintos componentes do meio físico e antrópico, em interação. Foram feitas análises de água, no sentido de apontar o nível de poluição hídrica gerado pelos dejetos. Os resultados apontaram que o meio hídrico da região apresenta características químicas e biológicas alteradas, embora os níveis mais elevados tenham sido detectados à jusante da área urbana, onde o Rio Quilombo recebe maior carga poluidora.
\end{abstract}

Palavras-chave: poluição hídrica, contaminação por atividade suinícola.

\section{HYDRIC POLLUTION BY SWINE EXCREMENTS: A CASE STUDY AT RURAL PORTION OF QUILOMBO TOWN, SANTA CATARINA}

\begin{abstract}
The swinish activity, essential for the economy of many cities on the west of Santa Catarina, is contributing to unleash environmental problems, like the ones found in Quilombo city. The main residues resulted from this activity - the swine excrements - can be considered one of the biggest causes of pollution. In this sense this research evaluates the environmental impacts caused by excrements from the swinish activity in the hydric environment of the rural portion of Quilombo. The research is based on the systemic approach, allowing to analysis of the distinct environmental components, in interaction. The water was analyzed to assess the level of hydric pollution caused by excrements. The conclusion of the research, pointed that the hydric environment of the Quilombo basin shows chemical and biological characteristics altered, but, however, more significant alterations were found on the outskirt of the urban area, where Quilombo River receives a bigger polluter.
\end{abstract}

Key words: hydric pollution, contamination by swinish activity.

\footnotetext{
Parte da Dissertação de Mestrado apresentada ao curso de Pós-Graduação em Geografia - UFPR.

2 Mestre em Geografia, UFPR, e-mail: fabi.assis@bol.com.br

${ }^{3}$ Professora Doutora do Departamento de Geografia da UFPR, e-mail amuratori@uol.com.br
} 


\section{INTRODUÇÃO}

Nos dias atuais, uma das grandes questões relativas à problemática ambiental diz respeito à preservação da água doce em quantidade e qualidade para o consumo humano atual e futuro.

Os recursos hídricos superficiais e subterrâneos podem sofrer, em maior ou menor grau, contaminações pelos mais diversos poluentes. Dentre as principais fontes de contaminação dos recursos hídricos, encontram-se os resíduos das atividades industriais e agrícolas, além dos resíduos domésticos. Em áreas onde a pecuária está presente, existe uma maior ou menor contaminação, que está na dependência de uma série de fatores, envolvendo discernimento do criador, aplicação de recursos, tamanho da propriedade, assistência de órgãos responsáveis, além de condições ambientais propícias, especialmente quando se trata da criação de animais confinados. O confinamento é uma prática utilizada na suinocultura para a qual, a proximidade de fontes de água torna-se imprescindível, determinando, na maioria das vezes, a sua contaminação.

É preciso ressaltar que apesar desta circunstância negativa, as atividades suinícolas desempenham um papel de grande relevância no contexto econômico nacional.

Historicamente, a suinocultura catarinense desenvolveu-se com base na produção familiar. A partir da década de 1940, iniciou-se o processo de industrialização, aumentando consideravelmente a quantidade de produtores de suínos (VOTTO, 1999).

Até a década de 1970, os dejetos de suínos não eram considerados um fator preocupante, pois a concentração de animais era pequena e os solos das propriedades tinham capacidade para absorvê-los. Com o aumento da produtividade e o crescimento das áreas urbanas próximas aos locais de criação dos suínos, este quadro mudou. A preocupação com a poluição do ambiente e, de maneira especial, com os recursos hídricos, tornou a destinação de dejetos de suínos uma ameaça à sobrevivência e expansão da atividade suinícola, tendo em vista que o aumento da produção não veio acompanhado de medidas no sentido de minimizar os prejuízos causados ao meio ambiente. $\mathrm{Na}$ atualidade, o plantel catarinense, pelo seu tamanho, representa um volume de aproximadamente 10 milhões de metros cúbicos de dejetos líquidos produzidos por ano (EMBRAPA, 2005).

Considerando essas premissas, a avaliação dos recursos hídricos é uma necessidade premente que exige atenção das autoridades sanitárias e órgãos ambientais, a fim de preservar a qualidade da água para o consumo humano.

Dada a relevância do assunto, o mesmo foi escolhido como tema do presente estudo. Para a sua realização, foi delimitada a área rural do município de Quilombo, correspondente à bacia hidrográfica do rio Quilombo, localizado na região oeste do estado de Santa Catarina, tendo em vista que a atividade suinícola é uma das mais importantes atividades econômicas deste município.

Nesse contexto, o estudo teve como objetivo geral avaliar a qualidade das águas do rio Quilombo, considerando a emissão de dejetos em seu leito, provenientes da atividade suinícola na área rural do município de Quilombo. Para atingir esse propósito, foram feitas análises laboratoriais da água do rio Quilombo, coletadas em diversos pontos da bacia, buscando-se identificar agentes poluidores que pudessem interferir na qualidade da água. Além disso, avaliou-se a relação da sociedade local com a problemática existente. 


\section{A SUINOCULTURA NO BRASIL E EM SANTA CATARINA}

O suíno doméstico é considerado um descendente dos javalis, catalogado ao gênero Sus e originário da Ásia, Europa e África, destacando-se por ser um dos primeiros animais domesticados.

Os suínos chegaram à América no final do século XV, junto com Colombo e no Brasil, em meados do século XVI. No estado de Santa Catarina a criação de porcos estabeleceu-se como alternativa à criação de grandes animais pelos povoadores paulistas, em função da falta de acesso e meios de transporte, e a fácil adaptação daquela espécie animal às características de relevo do oeste do estado, formado, em parte, por encostas íngremes e declividades acentuadas (PERTILE, 2001).

De acordo com a mesma autora, o período compreendido entre as décadas de 1940 e 1960 caracterizou-se pelo surgimento de grandes frigoríficos processadores de suínos. Neste período, o oeste catarinense já abastecia com carne suína e derivados os grandes mercados urbanos do centro-sul brasileiro. Procurando aumentar a disponibilidade de matéria-prima no oeste catarinense, a partir de meados da década de 1950, os frigoríficos começaram a interferir no processo de criação de suínos. Nesta época, com a melhoria dos transportes terrestre e aéreo, produtos derivados, considerados mais nobres, puderam chegar ao mercado com maior rapidez.

Conforme a autora acima (2001), ao longo da década de 1980, o processo de articulação industrial caracterizou-se pela intensificação do processo de integração, observando-se o aumento de produção das próprias agroindústrias e, posteriormente, o aumento na escala de produção a um menor número de produtores. A produção nacional de carne suína passou a apresentar índices consideráveis de crescimento nos últimos 23 anos (em torno de 4,5\% ao ano). A evolução do rebanho e o número de abates, bem como a de produção de suínos no Brasil, entre os anos de 1980 e 2004, estão expostos na tabela 1.

TABELA 1: EVOLUÇÃO DO REBANHO, ABATE E PRODUÇÃO DE SUÍNOS NO BRASIL (19802004 )

\begin{tabular}{|c|c|c|c|c|c|c|c|}
\hline DISCRIMINAÇÃO & 1980 & 1990 & 2000 & 2001 & 2002 & 2003 & 2004 \\
\hline REBANHO* & 32,50 & 30,00 & 37,30 & 37,50 & 38,00 & 38,00 & 33,15 \\
\hline ABATE* & 17,70 & 16,00 & 32,30 & 34,90 & 37,60 & 35,60 & 28,18 \\
\hline CONS. PER CAPITA (KG) & 9,67 & 7,05 & 14,30 & 14,30 & 13,80 & 13,00 & 13,00 \\
\hline PROD. CARNE** & 1.150 & 1.040 & 2.556 & 2.730 & 2.872 & 2.791 & 2.750 \\
\hline IMPORTAÇÃO** & 1,00 & 2,00 & 5,00 & 2,00 & 1,00 & 1,00 & 1,00 \\
\hline EXPORTAÇÃO** & 0,20 & 13,10 & 127,9 & 265,20 & 475,90 & 491,5 & 507,70 \\
\hline POPULAÇÃO & 119,00 & 146,0 & 169,8 & 172,00 & 174,20 & 176,5 & 181,60 \\
\hline
\end{tabular}

*milhões de cabeças / ** mil toneladas

FONTE: ACCS, 2005.

Aproximadamente $65 \%$ do abate de suínos do país são feitos nas indústrias localizadas, em sua maioria, na região sul do Brasil, sob inspeção federal do Ministério da Agricultura, Pecuária e Abastecimento (MAPA). Outros 35\% dos abates inspecionados ficam a cargo das inspeções estaduais e municipais.O abate inspecionado de suínos no Brasil é demonstrado na tabela 2. 
TABELA 2 - ABATE DE SUINOS NO BRASIL EM 2004 (INSPECIONADOS)

\begin{tabular}{l|l|l}
\hline ESTADOS & ABATE $*$ & $\%$ \\
\hline SANTA CATARINA & 6.757 .666 & 20,00 \\
\hline RIO GRANDE DO SUL & 4.508 .309 & 13,30 \\
\hline PARANÁ & 3.425 .012 & 10,10 \\
\hline MINAS GERAIS & 1.625 .921 & 4,80 \\
\hline SÃO PAULO & 1.191 .158 & 3,50 \\
\hline GOIÁS & 997.201 & 3,00 \\
\hline MATO GROSSO DO SUL & 683.322 & 2,00 \\
\hline MATO GROSSO & 554.711 & 1,70 \\
\hline OUTROS & 14.174 .811 & 41,60 \\
\hline TOTAL & 33.918 .111 & 100,00 \\
\hline
\end{tabular}

* milhões de cabeças

FONTE: ABIPECS, 2005.

Conforme pode ser observado, dentre os estados brasileiros, Santa Catarina destaca-se na realização de abates inspecionados, com $20,0 \%$, seguida pelo estado do Rio Grande do Sul, com 13,3\%, e Paraná, representando 10,1\%.

Segundo a Empresa Brasileira de Pesquisa Agropecuária (EMBRAPA, 2005), dentre os oito maiores estados produtores de suínos, Santa Catarina é aquele de menor superfície, o que lhe atribui um índice de concentração da produção muito grande em relação aos demais.

Se, por um lado, é importante garantir a lucratividade da atividade suinícola e a continuidade desse tipo de agronegócio que envolve diretamente, 150.000 pessoas em Santa Catarina, não se pode esquecer que as áreas de risco de poluição causada pelos dejetos de suínos abrangem praticamente todas as regiões desse estado, que possui mais de 5,5 milhões de habitantes. Além desses, outros milhões de habitantes estão localizados em áreas de risco, pela interligação dos rios e lençóis subterrâneos, destacando-se o Aqüífero Guarani, com 1,2 milhões de $\mathrm{km}^{2}$, sobre o qual se localizam mais de 15 milhões de habitantes do Brasil, Paraguai, Uruguai e Argentina (SEGANFREDO, 2002).

\section{CARACTERÍSTICAS DO MEIO FÍSICO E ANTRÓPICO DO MUNICÍPIO DE QUILOMBO}

A geologia, o clima e o relevo compreendidos no sistema ambiental da área estudada exercem forte influência sobre a formação e distribuição dos solos, e sobre o ciclo hidrológico, interferindo de forma acentuada nos sistemas de produção agrícola, nas estratégias de zoneamento de cultivos, criações, e no manejo de resíduos e efluentes gerados pela criação de animais em confinamento.

A geologia da bacia hidrográfica do rio Quilombo é homogênea e semelhante à de toda a região oeste do estado de Santa Catarina. De acordo com Testa e Espírito Santo (1992) compreende rochas vulcânicas de idade Juro-Cretácea, oriundas de uma sucessão de derrames basálticos, caracterizados por uma seqüência básica predominante nos níveis de cotas mais baixas, e uma seqüência ácida nas cotas mais elevadas do terreno.

Sobre esses materiais atua um clima regional do tipo mesotérmico úmido (Cfa - clima temperado chuvoso, sem estação seca, com verão quente), conforme classificação de 
Koeppen, com precipitação média mensal do mês mais seco entre 50 e 90 milímetros $(\mathrm{mm})$, e precipitação média anual superior a $1.700 \mathrm{~mm}$.

Conforme dados da Estação Pluviométrica da EPAGRI, unidade de Chapecó, SC (2005), a média anual de precipitação dos últimos dez anos no oeste do estado de Santa Catarina variou entre $1.708 \mathrm{~mm}$ e $2.953 \mathrm{~mm}$. Em relação ao município de Quilombo, o menor índice pluviométrico, de $1.739 \mathrm{~mm}$, foi registrado no ano de 1999, e o maior, de $2.795 \mathrm{~mm}$, no ano de 1996.

$\mathrm{Da}$ interação das litoestruturas e do clima resultou um relevo correspondente ao Planalto Ocidental catarinense, formado por patamares cortados por vales fluviais. A maior parte desses vales encontra-se voltada para o sul-sudoeste, dirigindo-se para os rios Uruguai e Pelotas, pertencentes à chamada Vertente do Interior (CARRARO, 2004). Apresenta-se em cerca de $20 \%$ de seu total como suavemente ondulado, em que a atividade agrícola pode ser desenvolvida sem restrições, no que se relaciona à mecanização das lavouras (SANTA CATARINA, 1997). O município de Quilombo está localizado na porção oeste desse Planalto Ocidental.

Peluso Junior (1991) define que "o planalto do oeste tem 1.200 metros de altitude nas cabeceiras do rio Chapecó e menos de 300 metros em sua foz no rio Uruguai”. Portanto, são $900 \mathrm{~m}$ de declive entre a nascente e a foz do rio Chapecó, sendo que o município de Quilombo encontra-se em meio a este trajeto, a 425 metros de altitude.

A região da pesquisa corresponde à área rural da bacia hidrográfica do rio Quilombo, afluente do rio Chapecó, e pertencente à bacia do rio Uruguai. O rio Uruguai, por sua vez, faz parte da bacia Platina que é a segunda maior bacia hidrográfica da América do Sul.

\section{FIGURA 1: REDE HIGROGRÁFICA DO ESTADO DE SANTA CATARINA}

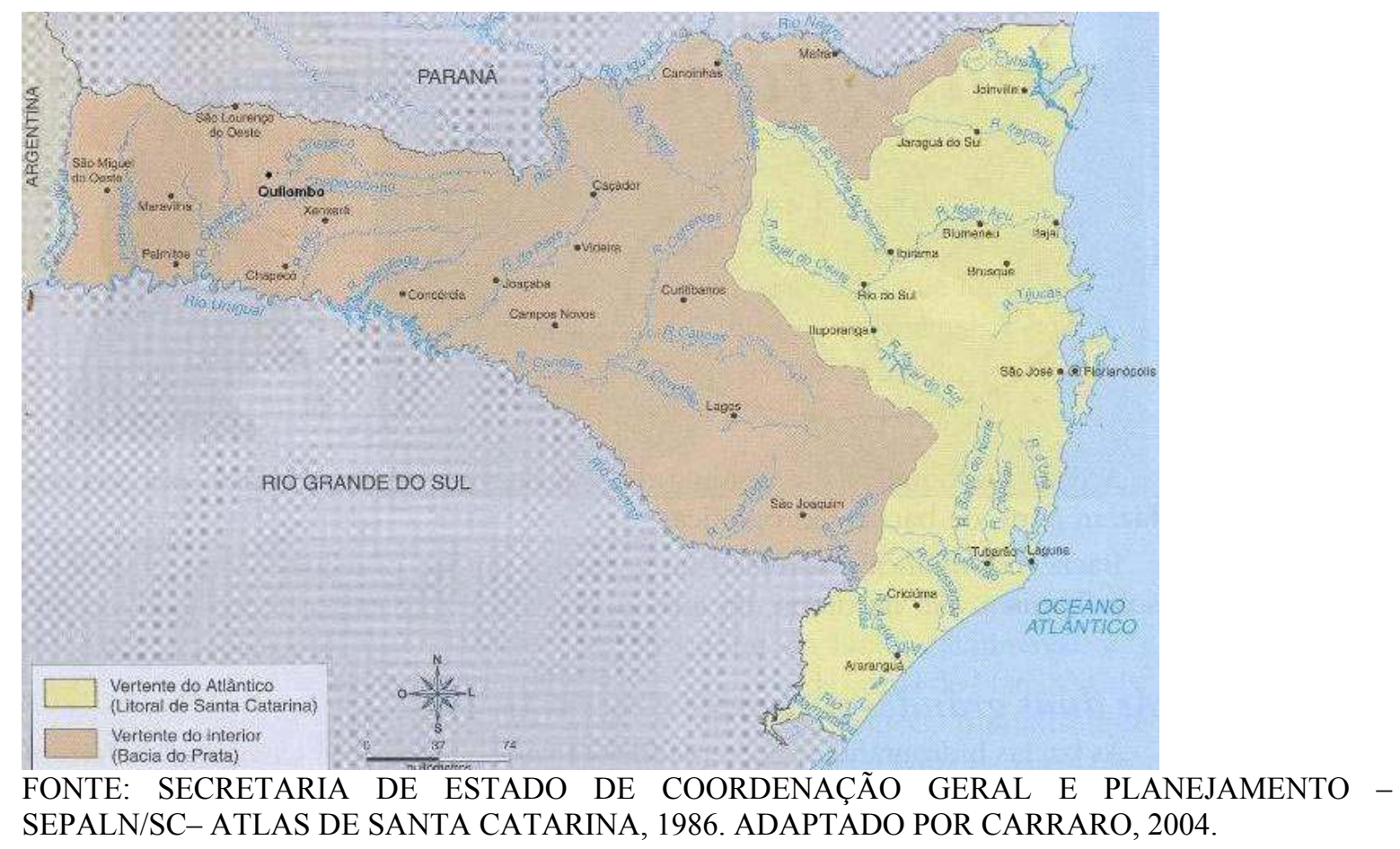


A bacia do rio Quilombo tem uma área de drenagem de 4.517 hectares $\quad\left(45,17 \mathrm{~km}^{2}\right)$, com um perímetro total de 32.988 metros. Em relação à ordem dos rios, é definida como uma bacia de terceira ordem, segundo a classificação apresentada por Strahler ${ }^{4}$ (1964), citada por Christ (2003, p. 31).

Em relação aos solos, pode-se considerar que no oeste de Santa Catarina, são encontradas cinco classes principais de solos e quatorze unidades de mapeamento. No caso do Planalto Dissecado do rio Uruguai, onde o rio Quilombo está inserido, são encontradas associações de solos originados do basalto, destacando-se os Cambissolos, Neossolos Litólicos, Nitossolos e Chernossolos Argilúvicos.

A combinação do arcabouço geológico, do relevo e da cobertura superficial em presença de um clima úmido permitiu o desenvolvimento de duas formações florestais na área da pesquisa: a Floresta Ombrófila Mista em altitudes até $500 \mathrm{~m}$. e a Floresta Estacional em altitudes inferiores a essa cota. No município de Quilombo, essa vegetação primária encontra-se, atualmente, bastante degradada, com exceção de algumas pequenas áreas, apresentando um valor econômico reduzido, uma vez que a maior parte da floresta primária foi devastada pela atuação de madeireiras. A vegetação secundária é formada basicamente por samambaias (Polypodium aureum), capim rabo-de-burro (Andropogon bicornis), vassoura (Dodonaea viscosa), bracatinga (Mimosa scabrella bentham) e canela (Cinnamomum zeylanicum).

Nos aspectos referentes à ocupação da área, e conforme dados do censo demográfico realizado pelo IBGE (2000), o município de Quilombo contava com uma população de 10.736 habitantes, dos quais 6.039 habitantes encontravam-se na área rural. $O$ último dado populacional disponível do município de Quilombo é do ano de 2005 (mês de julho), apresentando uma população total de 10.066 habitantes (IBGE, 2005).

\section{MATERIAL E MÉTODOS}

\section{LOCALIZAÇÃO DA ÁREA DE ESTUDO}

A área de estudo abrange o município de Quilombo, localizado na região oeste do estado de Santa Catarina (Figura 2), com coordenadas na porção central do sítio urbano de $26^{\circ}$ 43' 34' de Latitude Sul e 52 43' 1' de Longitude Oeste, a 425 metros de altitude em relação ao nível do mar. Possui uma área de $279 \mathrm{~km}^{2}$, fazendo divisa, ao norte, com Formosa do Sul e Santiago do Sul; ao leste com São Domingos, Entre Rios e Marema; ao sul com Coronel Freitas; e a oeste com União do Oeste e Jardinópolis.

\footnotetext{
${ }^{4}$ STRAHLER, A. N. Qualitative analysis of watershed geomorphology. Transactions of American Geophysical Union, New York, v. 38, p. 913 - 920, 1964.
} 
FIGURA 2: LOCALIZAÇÃO DO MUNICÍPIO DE QUILOMBO NO ESTADO DE SANTA CATARINA

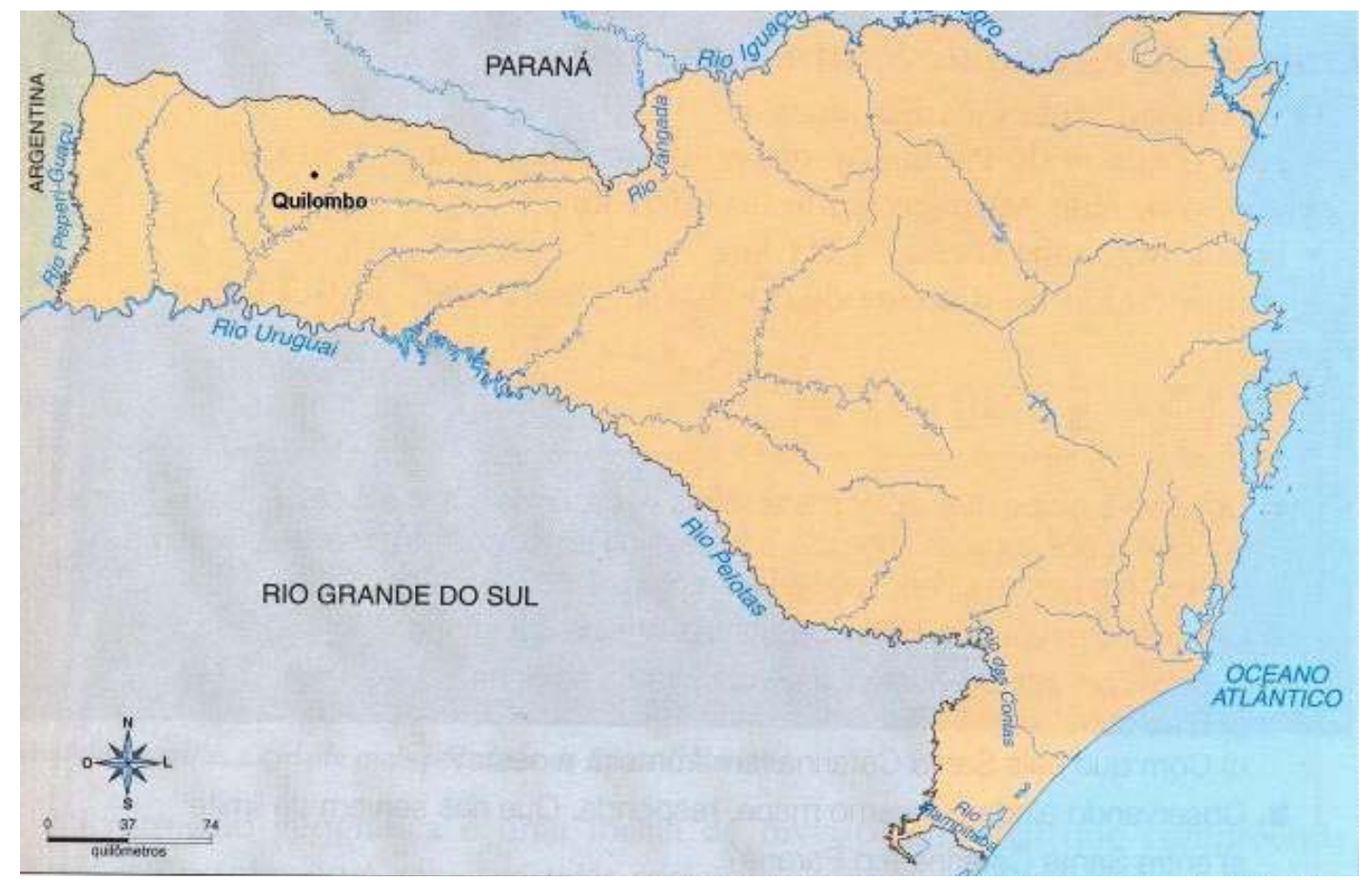

FONTE: ATLAS DO ESTADO DE SANTA CATARINA. ADAPTADO POR CARRARO, 2004.

\section{METODOLOGIA E PROCEDIMENTOS METODOLÓGICOS}

Para atingir os objetivos propostos fez-se um diagnóstico da área de estudo, realizando-se análises da qualidade de água do rio Quilombo, além da aplicação de entrevistas entre os proprietários envolvidos. A abordagem sistêmica foi aplicada, e sua escolha foi determinada, tendo em vista que a mesma facilita o estudo da relação entre os elementos do meio ambiente, não isolando os elementos naturais dos antrópicos. Na pesquisa, trabalhou-se com as seguintes variáveis: clima (precipitação), solo, relevo, vegetação e ação antrópica.

De acordo com Lima (1996), a bacia hidrográfica pode ser considerada um sistema geomorfológico aberto, recebendo fluxos de matéria e energia de acordo com as condições geomorfológicas e climáticas presentes, e perdendo continuamente energia matéria através do deflúvio, podendo assim, ser descrita em termos de variáveis interdependentes, as quais oscilam ao longo de um padrão, ou de uma média. Foram considerados os fluxos de matéria e energia, concretizados pela pluviosidade, a água do rio, os poluentes e o seu trânsito pela bacia hidrográfica, indo poluir as águas.

Foram utilizados diversos documentos cartográficos, tais como cartas topográficas da área, na escala 1: 50.000 ( $1{ }^{\mathrm{a}}$ Divisão de Levantamento do Exército, vetorizadas pela Secretaria de Desenvolvimento Urbano e Meio Ambiente do Governo de Santa Catarina, de 1978); Mapa Rodoviário do Município de Quilombo, elaborado pela Associação dos Municípios do Oeste de Santa Catarina (AMOSC), na escala 1:70.000, de abril de 2002; Imagens de satélite LANDSAT 7 / ETM), nível 1 G de correção geométrica, bandas 3, 4, 5, separadas; órbitas 222, ponto 79 (com deslocamento), de 15 de março de 2002, formato TIF.

Quanto aos procedimentos, em primeiro lugar, fez-se o planejamento das ações, de 
maneira a integrar todos os dados obtidos, relacionando-os com o objetivo geral da pesquisa. Para tanto, foram levantadas todas as informações necessárias, com destaque para uma avaliação do meio biofísico, socioeconômico e cultural da área-objeto da pesquisa, ou seja, na área rural, compreendida na bacia hidrográfica do rio Quilombo.

$\mathrm{Na}$ seqüência, foram identificados os locais de criação dos suínos, com especial atenção para as esterqueiras, origem da poluição dos dejetos. Essa identificação espacial das esterqueiras definiu os locais para coleta de amostras de água. E, para a verificação da qualidade da água do rio Quilombo foram escolhidos seis pontos ao longo do curso, sendo quatro deles localizados a montante da área urbana, e os outros dois, a jusante (Figura 3).

FIGURA 3: LOCALIZAÇÃO DOS PONTOS DE COLETA DE ÁGUA NA BACIA HIDROGRÁFICA DO RIO QUILOMBO

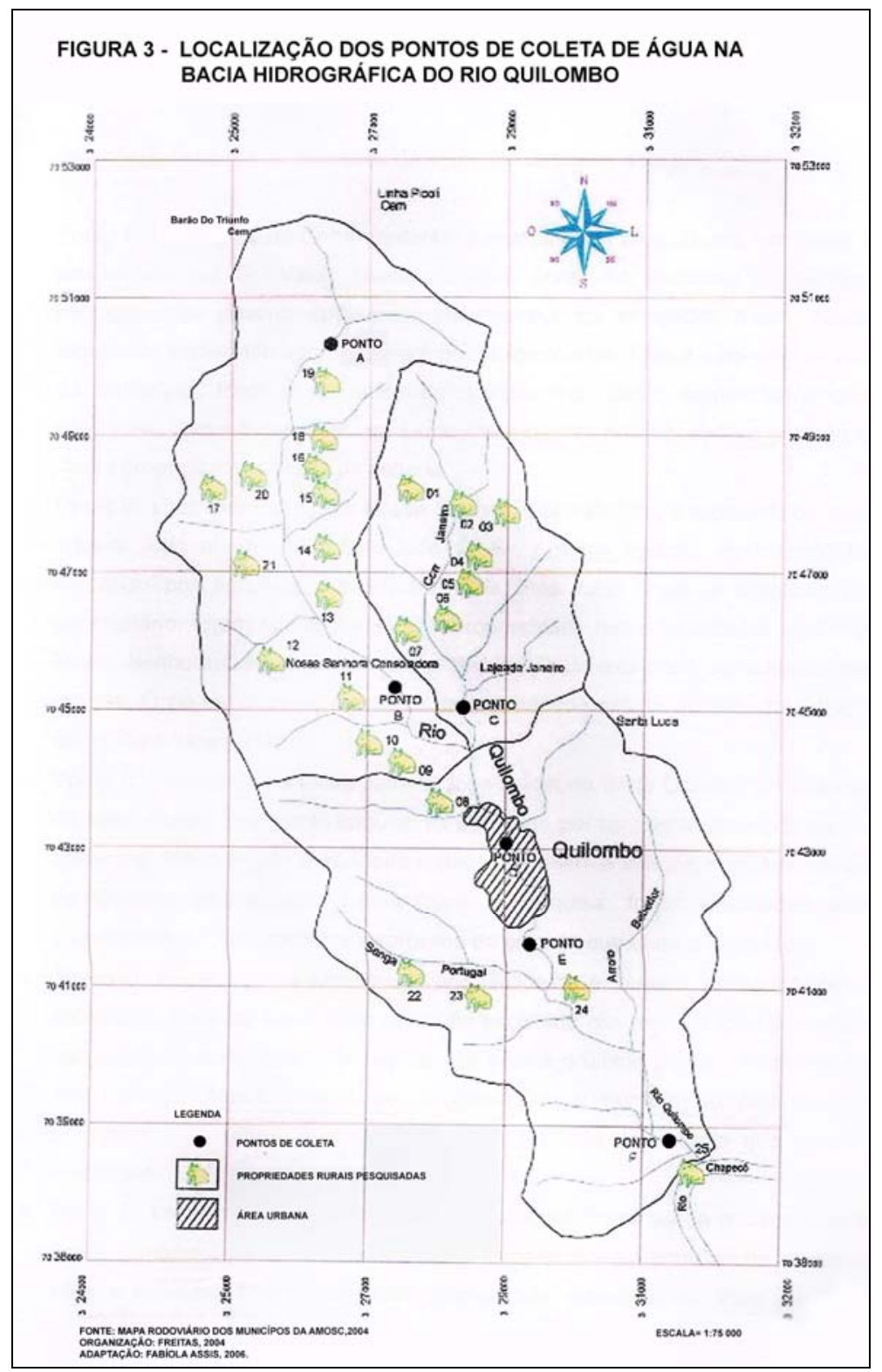

FONTE: MAPA RODOVIÁRIO DOS MUNICÍPIOS DA AMOSC, 2004 
A primeira coleta de água para análise foi realizada no dia 18 de maio de 2005 , e a segunda, no dia 13 de outubro de 2005, considerando-se dois períodos distintos, outono e primavera, de maneira a abranger um período mais seco (maio) e outro mais úmido (outubro).

Após a realização das coletas verificou-se que, durante o mês de maio, o índice pluviométrico foi de $212 \mathrm{~mm}$; já no mês de outubro, o mesmo foi de $424 \mathrm{~mm}$, o que comprovou a variação pluviométrica existente entre ambos os períodos do ano (SECRETARIA MUNICIPAL DE AGRICULTURA DE QUILOMBO, 2005).

Para realizar o controle da poluição das águas de rios e reservatórios, utilizam-se os padrões de qualidade que definem os limites de concentração de cada substância presente na água. Entretanto, esses padrões dependem da classificação das águas interiores, que é estabelecida segundo seus usos preponderantes, por legislação específica, variando da classe especial, a mais nobre, até a classe 4, a menos nobre (CETESB, 2005). O rio Quilombo, pelas suas características e de acordo com a Resolução ${ }^{\circ} .357$, de 17 de março de 2005, do CONAMA (Conselho Nacional do Meio Ambiente), é de classe 2 (águas destinadas ao abastecimento doméstico, após tratamento convencional; à irrigação de hortaliças ou plantas frutíferas e à recreação de contato primário: natação, esqui-aquático e mergulho).

Complementando essa classificação, tem-se a Resolução no . 357, de 17 de março de 2005, do CONAMA, que estabelece as condições e padrões de lançamento de efluentes e o Decreto Estadual $\mathrm{n}^{\circ}$. 14.250, de 5 de junho de 1981, referente à proteção e a melhoria da qualidade ambiental.

Quanto à realização das análises de água, foram eleitos os indicadores baseados no IQA Índice de Qualidade das Águas (CETESB, 2005) tendo sidos subdivididos em químicos, físicos e biológicos. Os indicadores analisados pertencentes ao primeiro grupo foram: $\mathrm{pH}$, condutividade, $\mathrm{DBO}_{5}$, oxigênio dissolvido, fósforo total, nitrogênio e nitrato. Os indicadores físicos analisados foram turbidez e sólidos totais, e os indicadores biológicos, coliformes totais, descritos a seguir:

- $\mathrm{O}$ pH indica a acidez ou alcalinidade da solução. Um valor de $\mathrm{pH} 7$ indica uma solução neutra e índices de pH maiores de 7 são básicos, e os abaixo de 7 são ácidos.

- O indicador condutividade elétrica demonstra a capacidade que a água possui em conduzir corrente elétrica. Este indicador está relacionado com a presença de íons dissolvidos na água. Quanto maior for a quantidade de íons dissolvidos, maior será a condutividade elétrica da água. Seu conhecimento contribui para a detecção de possíveis impactos ambientais que ocorram na bacia de drenagem, ocasionados por lançamentos de resíduos industriais, esgotos, etc.

- A demanda bioquímica de oxigênio $\left(\mathrm{DBO}_{5}\right)$ exprime o valor da poluição produzida por matéria orgânica oxidável biologicamente, e corresponde à quantidade de oxigênio que é consumida pelos microorganismos do esgoto ou águas poluídas, na oxidação biológica, quando mantida a uma dada temperatura por um espaço de tempo convencionado. $\mathrm{O}$ teste de $\mathrm{DBO}_{5}$ requer no mínimo 5 dias, correspondente ao período de incubação. É o indicador mais comumente utilizado para a medida do consumo de oxigênio na água.

- Os coliformes totais estão presentes em grande quantidade nas fezes do ser humano e 
dos animais de sangue quente. Portanto, a presença das bactérias coliformes na água de um rio significa que esse rio recebeu matérias fecais, mas não exclusivamente humanas. $\mathrm{O}$ valor permitido não pode ultrapassar 5.000 a cada $100 \mathrm{ml}$.

- O nitrato é a principal forma de nitrogênio associada à contaminação da água pelas atividades agropecuárias. Na suinocultura, o nitrato presente nos dejetos é altamente poluente.

- O indicador nitrogênio, dependendo de quantidade, torna-se importante, pois é responsável pela alimentação de algas, vegetais superiores e outros organismos aquáticos. No entanto, em dosagens elevadas, pode provocar sérios problemas, como proliferação excessiva de algas, causando o fenômeno conhecido como eutrofização (boa nutrição) de lagos e represas. Conforme a Resolução nº 357 do CONAMA, o indicador nitrogênio deve apresentar valor máximo de $3,7 \mathrm{mg} / \mathrm{L}$, para $\mathrm{pH} \leq 7,5$, para enquadrar-se nos valores máximos admissíveis.

- O fósforo apresenta-se na água principalmente nas formas orgânica e inorgânica. É um elemento essencial para o crescimento de algas, porém, quando em elevadas concentrações em lagos e represas, pode conduzir a um crescimento exagerado desses organismos. Para o indicador fósforo total, tem-se uma referência de até 0,1 $\mathrm{mg} / \mathrm{L}$ para rios de classe 2 .

- Os sólidos podem ser orgânicos e inorgânicos, e podem ser classificados de acordo com as suas características físicas ou químicas. Em elevadas concentrações, os sólidos totais podem resultar em problemas estéticos, depósitos de lodo e proteção de patogênicos (SIBAC, 2005).

- O oxigênio dissolvido é vital para os seres aquáticos aeróbios e é o principal indicador de caracterização dos efeitos da poluição das águas por despejos orgânicos. Caso o oxigênio seja totalmente consumido, têm-se as condições anaeróbias (ausência de oxigênio), com geração de maus odores (SIBAC, 2005)

As amostras de água foram encaminhadas ao Laboratório de Análises de Água da EPAGRI (Empresa de Pesquisa Agropecuária e Extensão Rural de Santa Catarina S. A.), unidade de Chapecó, em função da proximidade com o município de Quilombo. As baterias de análises das amostras de água foram realizadas pelo engenheiro químico Gary Bittencourt, funcionário da AMOSC (Associação dos Municípios do Oeste de Santa Catarina), com equipamentos pertinentes a cada indicador a ser analisado.

$\mathrm{Na}$ interpretação dos indicadores foram levados em consideração fatores importantes, tais como: a qualidade das águas que é modificada ao longo do ano, em função de fatores meteorológicos e da eventual sazonalidade de lançamentos poluidores e das vazões; à medida que as águas do rio se deslocam em direção à foz, a qualidade tende a melhorar por duas causas: a capacidade de autodepuração do próprio rio e a diluição dos contaminantes pelo recebimento de água de melhor qualidade de seus afluentes. Esta recuperação, entretanto, atinge apenas os níveis de qualidade aceitável ou boa. É muito difícil a recuperação ser total (CETESB, 2005).

Com o objetivo de realizar um levantamento quanto às características das propriedades rurais localizadas na bacia hidrográfica pesquisada, e de avaliar a relação da sociedade local com a problemática existente, no que se refere à poluição hídrica causada por dejetos de suínos, procedeu-se à aplicação de um questionário a 25 produtores rurais do município 
de Quilombo. A bacia hidrográfica do rio Quilombo conta com aproximadamente 170 propriedades; dentre estas, foram escolhidas para a pesquisa as maiores propriedades, do ponto de vista de amostragem. O questionário foi aplicado no dia 24 de março de 2005 , e contou com 14 perguntas.

Através da aplicação do questionário, foram levantados dados relativos às características gerais do produtor (idade, grau de escolaridade, fatores limitantes para o aumento da produção); da propriedade (área, distância média da propriedade à sede do município); da assistência técnica recebida, do rebanho (tamanho), de comercialização (destino da produção); de infra-estrutura (materiais usados nas construções das esterqueiras), além de outras questões, como locais de destino dos dejetos, existência de licenciamento ambiental na propriedade, origem da água para consumo doméstico e medidas atualmente adotadas e/ou que serão implementadas pela granja no controle da qualidade ambiental.

\section{RESULTADOS E DISCUSSÃO}

Os resultados obtidos nas análises de água do rio Quilombo, bem como os valores máximos permissíveis, conforme legislações ambientais em vigor no estado de Santa Catarina, estão expressos nas tabelas 3 e 4 .

TABELA 3: RESULTADOS DAS ANÁLISES DE ÁGUA DO RIO QUILOMBO REALIZADAS NO DIA $18 / 05 / 2005$

\begin{tabular}{|c|c|c|c|c|c|c|c|}
\hline DATA & $18 / 05 / 2$ & & & & & & \\
\hline PONTOS & $\mathbf{A}$ & B & $\mathbf{C}$ & D & $\mathbf{E}$ & $\mathbf{F}$ & $\begin{array}{l}\text { Máximo } \\
\text { Permissível }\end{array}$ \\
\hline $\mathrm{pH}$ & 6,31 & 6,25 & 6,21 & 6,19 & 6,21 & 6,25 & $6,0-9,0$ \\
\hline Turbidez (UNT) & 0,70 & 0,74 & 0,62 & 1,24 & 1,74 & 1,17 & $100 \mathrm{UNT}$ \\
\hline $\begin{array}{l}\text { Condutividade } \\
(\mu . \mathrm{S} / \mathrm{cm})\end{array}$ & 0,21 & 0,16 & 0,16 & 0,16 & 0,17 & 0,17 & - \\
\hline DBO5 (mg/l) & - & 76,20 & 74,40 & 75,90 & 74,7 & 75,5 & $5 \mathrm{mg} / \mathrm{L}$ \\
\hline $\begin{array}{l}\text { Coliforme Total } \\
\text { (NMP/100 ml) }\end{array}$ & 14.670 & 14.210 & 32.550 & 27.550 & 68.670 & 46.110 & $5.000 \mathrm{NMP}$ \\
\hline $\begin{array}{l}\text { Coliforme Fecal } \\
(\mathrm{NMP} / 100 \mathrm{ml})\end{array}$ & 1.460 & 1.600 & 2.780 & 2.010 & 10.760 & 10.760 & $1.000 \mathrm{NMP}$ \\
\hline $\begin{array}{l}\text { Nitrato } \\
(\mathrm{mg} / \mathrm{L} \mathrm{N}-\mathrm{NO} 3)\end{array}$ & 0,18 & 0,15 & 0,06 & 0,09 & 0,12 & 0,15 & $10,0 \mathrm{mg} / \mathrm{L}$ \\
\hline $\begin{array}{l}\text { Nitrogênio Total } \\
(\mathrm{mg} / \mathrm{L})\end{array}$ & 2,625 & 3,50 & 1,75 & 0,875 & 3,50 & 1,75 & $3,7 \mathrm{mg} / \mathrm{L}$ \\
\hline $\begin{array}{l}\text { Fósforo Total } \\
(\mathrm{mg} / \mathrm{L})\end{array}$ & 0,20 & 0,13 & 0,19 & 0,17 & 0,17 & 0,17 & $0,1 \mathrm{mg} / \mathrm{L}$ \\
\hline $\begin{array}{l}\text { Sólido Total } \\
(\mathrm{mg} / \mathrm{L})\end{array}$ & 76 & 74 & 80 & 77 & 88 & 70 & $1.000 \mathrm{mg} / \mathrm{L}$ \\
\hline $\begin{array}{l}\text { Oxigênio } \\
\text { Dissolvido (mg/L) }\end{array}$ & 5,36 & 5,92 & 5,35 & 5,82 & 5,82 & 5,73 & $5 \mathrm{mg} / \mathrm{L}$ \\
\hline
\end{tabular}

FONTE: LABORATÓRIO DE ANÁLISES DE ÁGUA DA EPAGRI, 2005. 
TABELA 4 - RESULTADOS DAS ANÁLISES DE ÁGUA DO RIO QUILOMBO REALIZADAS NO DIA $13 / 10 / 2005$

\begin{tabular}{|c|c|c|c|c|c|c|c|}
\hline DATA & $13 / 10 / 2$ & & & & & & \\
\hline PONTOS & $\mathbf{A}$ & B & $\mathbf{C}$ & D & $\mathbf{E}$ & $\mathbf{F}$ & $\begin{array}{l}\text { Máximo } \\
\text { Permissível }\end{array}$ \\
\hline $\mathrm{pH}$ & 6,28 & 6,70 & 6,82 & 6,11 & 6,50 & 6,80 & $6,0-9,0$ \\
\hline Turbidez (UNT) & 4,0 & 11,0 & 10,0 & 18,0 & 16,5 & 12,8 & $100 \mathrm{UNT}$ \\
\hline $\begin{array}{l}\text { Condutividade }(\mu . \mathrm{S} / \mathrm{cm} \\
)\end{array}$ & 0,17 & 0,16 & 0,16 & 0,21 & 0,20 & 0,16 & - \\
\hline DBO5 (mg/l) & 2,4 & - & 3,8 & 6,2 & 2,5 & 3,8 & $5 \mathrm{mg} / \mathrm{L}$ \\
\hline $\begin{array}{l}\text { Coliforme Total } \\
(\mathrm{NMP} / 100 \mathrm{ml})\end{array}$ & 27.550 & 14.210 & 21.050 & 57.940 & 31.300 & 61.310 & $5.000 \mathrm{NMP}$ \\
\hline $\begin{array}{l}\text { Coliforme Fecal } \\
(\mathrm{NMP} / 100 \mathrm{ml})\end{array}$ & 1.100 & 860 & 2.010 & 3.320 & 5.520 & 8.450 & $1.000 \mathrm{NMP}$ \\
\hline $\begin{array}{l}\text { Nitrato } \\
(\mathrm{mg} / \mathrm{L} \mathrm{N}-\mathrm{NO} 3)\end{array}$ & 0,18 & 0,21 & 0,36 & 0,39 & 0,39 & 0,55 & $10,0 \mathrm{mg} / \mathrm{L}$ \\
\hline $\begin{array}{l}\text { Nitrogênio Total } \\
\text { (mg/L) }\end{array}$ & 0,175 & 0,875 & 0,175 & 0,437 & 0,875 & 0,175 & $3,7 \mathrm{mg} / \mathrm{L}$ \\
\hline Fósforo Total(mg/L) & 0,005 & 0,005 & 0,01 & 0,13 & 0,01 & 0,01 & $0,1 \mathrm{mg} / \mathrm{L}$ \\
\hline Sólido Total (mg/L) & 77 & 78 & 85 & 84 & 84 & 81 & $1.000 \mathrm{mg} / \mathrm{L}$ \\
\hline $\begin{array}{l}\text { Oxigênio } \\
\text { Dissolvido (mg/L) }\end{array}$ & \multicolumn{6}{|c|}{ Não realizado } & $5 \mathrm{mg} / \mathrm{L}$ \\
\hline
\end{tabular}

FONTE: LABORATÓRIO DE ANÁLISES DE ÁGUA DA EPAGRI, 2005.

Os resultados das análises relativas aos parâmetros que definem a qualidade da água na bacia hidrográfica do rio Quilombo mostraram uma realidade, em parte distinta daquelas premissas das quais se partiu, imaginadas no início da pesquisa. Em princípio, acreditavase que as atividades praticadas em quase todas as propriedades, seriam desencadeadoras de processos que conduziriam a níveis muito elevados de poluição das águas, pelos dejetos de suínos. No entanto, esses resultados, comentados a seguir, indicaram uma outra situação, conforme o que se segue:

- $\mathrm{O}$ pH se manteve dentro dos valores aceitos para cursos de água classe 2, que é o intervalo entre 6 e 9 .

- A turbidez apresentou-se dentro da faixa recomendada de valor (até 100 UNT) nos seis pontos.

- O indicador de condutividade manteve um comportamento similar ao $\mathrm{pH}$, mantendose entre 0,16 e $0,21 \mathrm{~S} / \mathrm{cm}$ nos seis pontos analisados.

- Em relação ao indicador $\mathrm{DBO}_{5}$ os valores apresentaram-se alterados na primeira coleta, entre os pontos B e F. Foram realizadas análises de somente 5 amostras do indicador $\mathrm{DBO}_{5}$, pois a estufa do laboratório da Epagri permite apenas 5 análises deste indicador.

- Nos coliformes encontrou-se o ponto mais crítico da pesquisa. Para os coliformes totais, enquanto as legislações federal e estadual limitam o número mais provável (NMP) em 5.000 a cada $100 \mathrm{ml}$, verificaram-se nos resultados, valores de até 68.670 (no ponto E, primeira coleta).

- Em relação aos coliformes fecais, cujos valores permitidos são de 1.000 a cada 100 $\mathrm{ml}$, verificaram-se valores fora dos limites permitidos em todos os pontos na primeira 
análise realizada (para que o ponto seja considerado classe 2), e nos pontos A, C, D, E e F na segunda análise. Tais resultados são indicativos de que o rio recebeu carga poluidora.

- O indicador nitrato encontrou-se dentro do permitido nos seis pontos analisados, variando entre 0,12 no ponto $\mathrm{E}$ (primeira coleta) e $0,55 \mathrm{mg} / \mathrm{L}$ no ponto $\mathrm{F}$ (segunda coleta).

- O nitrogênio total manteve-se dentro do limite nos seis pontos. Os pontos B e E (na primeira coleta) foram os que apresentaram pequeno aumento, atingindo $3,5 \mathrm{mg} / \mathrm{L}$ em ambos os pontos, ficando próximos ao limite permitido.

- Em relação ao fósforo total todos os pontos da primeira coleta apresentaram valores além do permitido, variando entre 0,2 e $0,19 \mathrm{mg} / \mathrm{L}$. Já na segunda coleta, apenas o ponto $\mathrm{C}$ apresentou valor superior ao permitido, alcançando $0,13 \mathrm{mg} / \mathrm{L}$. As águas drenadas em áreas agrícolas podem provocar a presença excessiva de fósforo em águas naturais, em virtude da aplicação de fertilizante no solo (CETESB, 2005).

- Em relação aos sólidos totais, os resultados obtidos variaram entre 74 no ponto B (primeira coleta) e $88 \mathrm{mg} / \mathrm{L}$ no ponto E (também na primeira coleta).

- Finalmente, quanto ao o oxigênio dissolvido, na única coleta realizada deste indicador, verificou-se que todos os valores encontraram-se dentro do valor permitido. Este indicador foi realizado somente na primeira bateria de análises, pois o aparelho medidor do indicador, pertencente ao laboratório, apresentou defeitos técnicos antes que fosse realizada a segunda coleta.

Quanto à aplicação do questionário aos produtores rurais do município, foi possível verificar que existe, entre os sujeitos entrevistados, uma uniformidade de opinião sobre a importância da conservação do meio ambiente, porém com um baixonível de percepção da poluição causada pela suinocultura. Atualmente, a maioria das propriedades utiliza os dejetos como forma de adubação de campo nativo destinado à pastagem.

Apesar da significativa concentração de suínos na área pesquisada, alguns proprietários alegaram diversos fatores como limitantes para o aumento da produção. O principal fator relatado foi a falta de mão-de-obra disponível. Os proprietários, em sua maioria, devem tal fator ao êxodo rural crescente, uma vez que os filhos, que antes trabalhavam na propriedade, juntamente com os pais, agora procuram "sair de casa" para estudar e investir no futuro profissional.

Observou-se que os sujeitos envolvidos com a atividade suinícola consideram relevante a importância constante do recebimento de informações ligadas à atividade, como forma de elevar o nível de conscientização, auxiliando na preservação do meio ambiente.

Uma outra questão verificada é a da saúde das pessoas envolvidas com produção de suínos. Dos 25 produtores pesquisados, $28 \%$ informaram a existência de determinados problemas de saúde entre as pessoas residentes nas propriedades. Dentre os problemas pulmonares apontados, dois produtores informaram apresentar intoxicação por agrotóxicos.

Em relação aos dejetos provenientes da atividade suinícola, tema principal do estudo. foi possível verificar que grande parte vem sendo estocada em esterqueiras para posterior distribuição nas lavouras. No entanto, essa estocagem tem problemas como pode ser verificado nos registros fotográficos (figuras 3 e 4), na seqüência. 


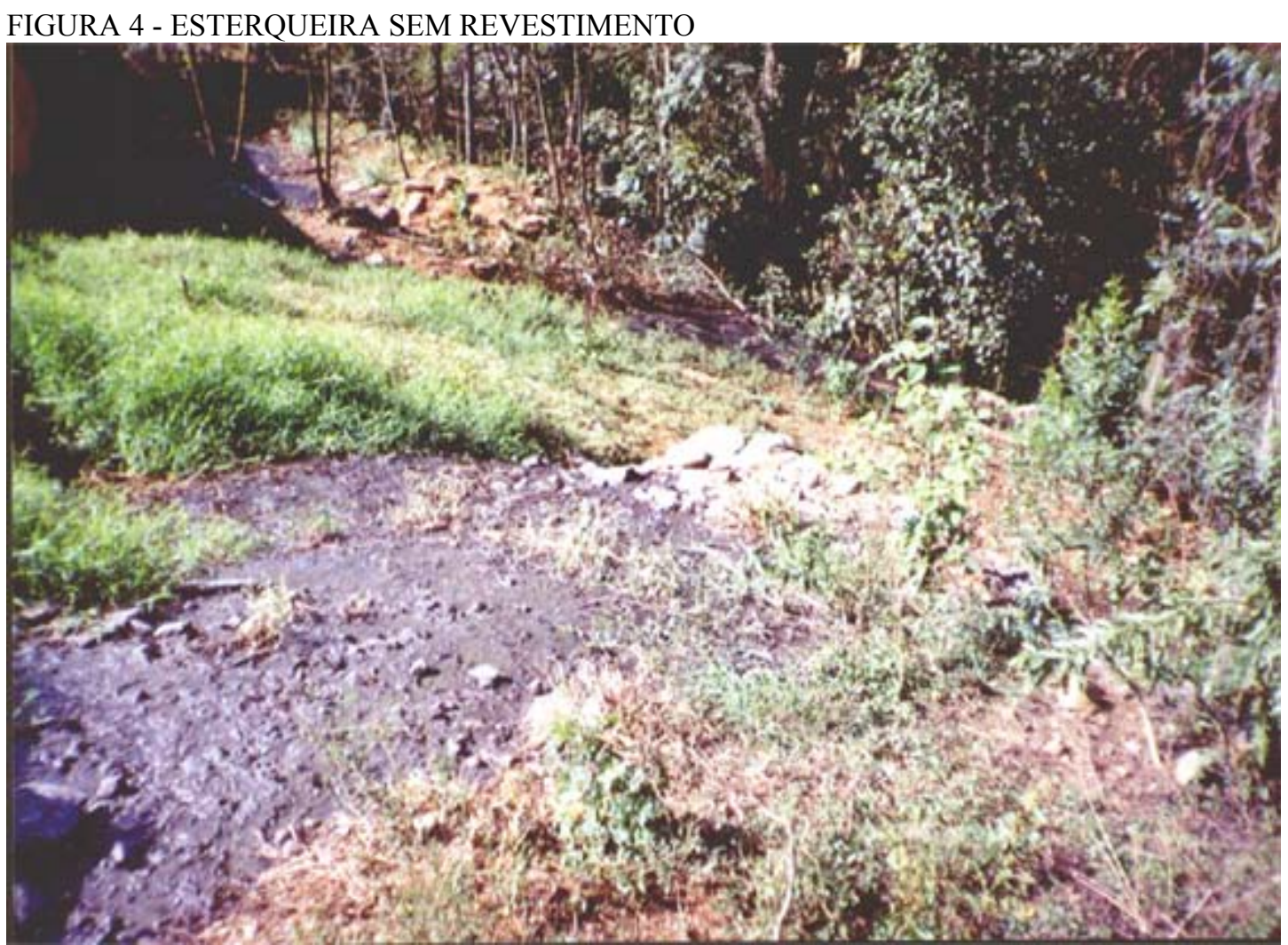

Dejetos escorrendo encosta abaixo, em direção ao vale do rio Quilombo.

FONTE: A AUTORA, 2004

FIGURA 5 - ESTERQUEIRA DE CONCRETO

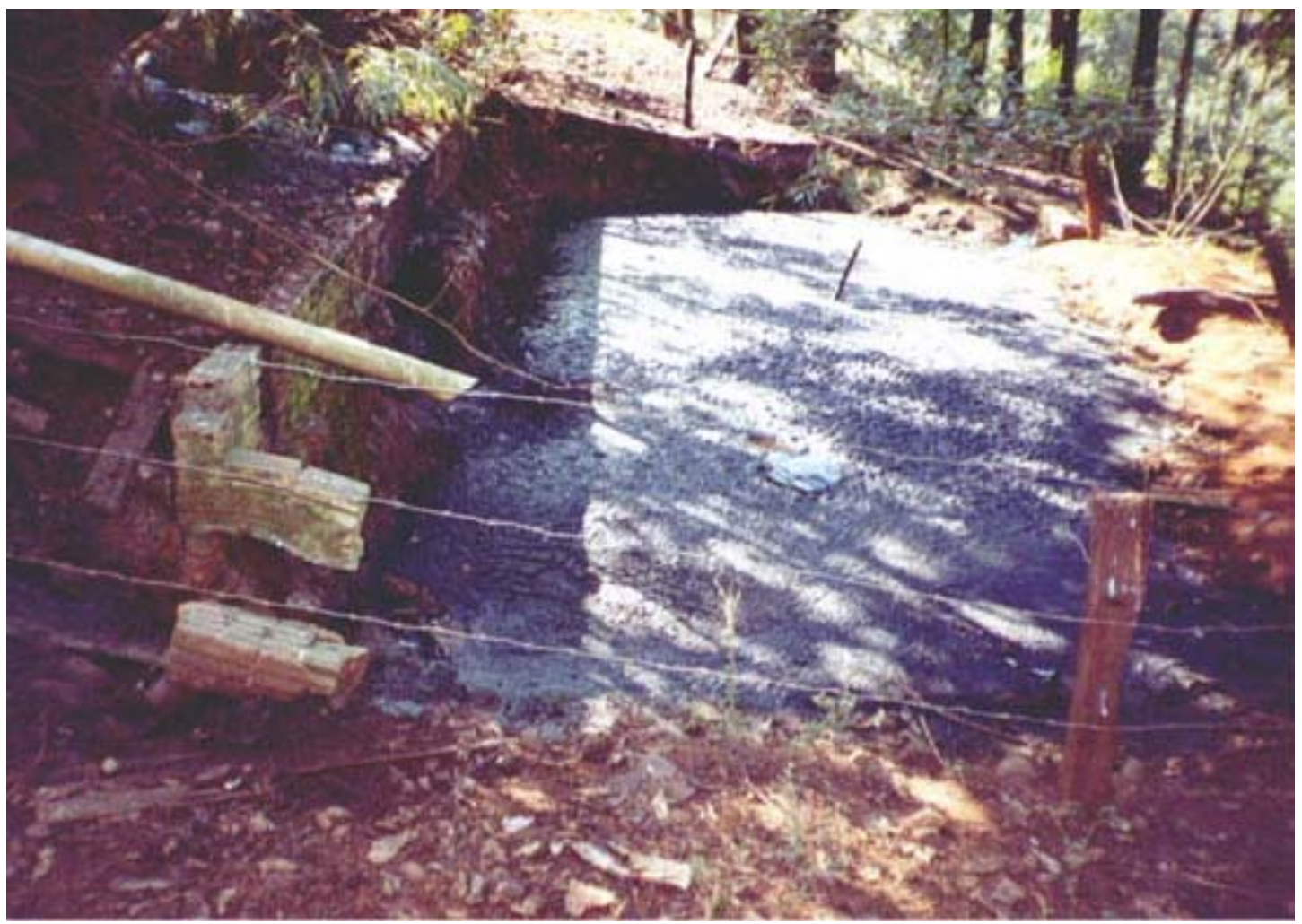

A esterqueira apresenta um volume maior que sua capacidade, determinando o extravasamento dos dejetos para o vale.

FONTE: A AUTORA, 2004. 
As perspectivas da atividade suinícola para o futuro é uma das questões que merece atenção: a maioria dos produtores opinou negativamente a respeito. Dentre os entrevistados, quatro informaram não possuir previsão para realizar investimentos na propriedade, embora não tenham extinguido tal possibilidade. Além destes, outros produtores informaram que pretendem abandonar a suinocultura para investir na educação profissional dos filhos, ou abandonar o município futuramente, e deslocar-se para um centro urbano maior.

Apesar da redução do número de produtores nas últimas décadas, aumentaram os rebanhos, o movimento econômico e o nível tecnológico empregado nas criações. Tais características refletem a mudança no perfil da suinocultura, que passou da subsistência ou pequena escala, para uma atividade empresarial, onde as agroindústrias e famílias são co-agentes do empreendimento.

Alguns produtores entrevistados informaram que a atividade não apresenta segurança financeira ao produtor, e que os custos dos suínos variam constantemente, dificultando a compra dos mesmos. Dos produtores, dois responderam que estão no limite máximo permitido para a produção, não apresentando, portanto, espaço físico disponível para o aumento da produção. Um dos produtores citou que as exigências ambientais são muito severas, e que mudam constantemente; este mesmo produtor rural alegou falta de conhecimentos específicos relativos à questão ambiental que norteia a suinocultura.

Apenas 36\% dos entrevistados afirmaram possuir boas perspectivas em relação à suinocultura.

E, finalmente, uma das questões que merece ser citada é relativa à legislação ambiental, obrigatória para todas as atividades agropecuárias que dispõem de mais de 160 animais confinados (incluídos os suínos). Constatou-se que apenas $60 \%$ das propriedades pesquisadas possuem a referida licença, e as demais informaram estar providenciado a mesma.

A atual legislação ambiental prevê penalidades aos criadores que não dão a devida destinação aos dejetos. O processo de licenciamento da produção leva tempo e é bastante oneroso. São necessárias licenças prévias de instalação e de operação do plantel, sendo que o valor de cada uma delas é dada em UFIRs $^{5}$ (cerca de $\mathrm{R} \$ 1,60$ ) e depende do número de cabeças de animais a serem criados e do sistema de criação.

Em relação às esterqueiras das propriedades pesquisadas, dezenove encontram-se abertas, cinco cobertas, e em um dos casos, os dejetos são encaminhados diretamente para a lavoura. Foi constatado que a maior parte delas encontra-se em situação regular, protegidas com concreto e lonas de PVC.

\section{CONCLUSÕES}

Um dos desafios da atividade suinícola, na atualidade, é a exigência da sustentabilidade ambiental. Há um consenso generalizado de que o setor da suinocultura deva adotar uma

\footnotetext{
${ }^{5}$ A UFIR, unidade fiscal de referência, é um índice usado para atualização monetária de tributos e multas; está baseada na Resolução SER nº. 156, de 21 de dezembro de 2004. Secretaria de Estado da Receita. Disponível em: <http://www.receita.rj.gov.br/sub_adj_rec/sear/valor_ufirrj.shtml>. Acesso em: 03 dez. 2005.
} 
postura de respeito à qualidade de vida e do meio ambiente, especialmente dos recursos hídricos.

Dentro desta concepção, esse estudo procurou mostrar alguns aspectos da produção de suínos vistos sob a ótica de proteção ao meio ambiente, relacionando-os especificamente ao problema da qualidade da água, na área rural do município de Quilombo. Buscou-se mostrar a realidade da suinocultura, como uma atividade presente na maioria das propriedades rurais do município, que emprega basicamente mão-de-obra familiar.

Ao se abordar a questão da poluição por dejetos de suínos, os produtores que têm suas propriedades em áreas da bacia hidrográfica do rio Quilombo reconhecem a necessidade de uma solução, mas, ao mesmo tempo, argumentam que a suinocultura não comporta os custos para atender os padrões estabelecidos pela legislação ambiental. Dentre os argumentos, foram destacados o custo do tratamento e o transporte dos dejetos. Cabe salientar, pois, que o tratamento dos dejetos depende da situação econômica do produtor, além das características geográficas das propriedades que vão determinar as diversas formas de manejo dos dejetos.

Avaliou-se ainda a relação da sociedade local com essa problemática existente. Através da aplicação de um questionário, observou-se que os sujeitos envolvidos com a atividade suinícola consideram relevante o recebimento de informações ligadas à atividade, como forma de elevar o nível de conscientização, auxiliando na conservação do meio ambiente.

Conforme citado anteriormente, as análises de água, realizadas em dois períodos distintos do ano de 2005, em condições climáticas distintas, demonstraram que os maiores índices de poluição não estão nas proximidades das propriedades rurais, mas sim, à jusante da área urbana. Tal fato é um indicativo claro de que os dejetos domésticos estão sendo jogados diretamente no rio Quilombo, de acordo com constatação feita durante os trabalhos de campo, o que, em princípio, não se cogitava abordar.

Apesar da situação exposta, a questão da poluição hídrica por dejetos de suínos no município de Quilombo deve ser merecedora de atenção. Tendo em vista que as análises de água apresentaram alguns valores fora dos padrões e, observando-se a taxa de concentração de suínos na área da bacia hidrográfica, sugere-se um plano de gestão ambiental, a fim de viabilizar a própria atividade e o manejo dos dejetos, evitando-se, com isto, a degradação.

É preciso deixar claro que a questão da poluição causada por dejetos de suínos não se constitui apenas em um problema que envolve o setor produtivo de suínos, mas tem interrelação com todas as atividades que, de certa forma, afetam a qualidade ambiental no município de Quilombo.

\section{REFERÊNCIAS}

BRASIL. Associação dos Municípios do Oeste Catarinense - AMOSC. Mapa rodoviário do município de Quilombo. Chapecó: Assessoria de Topografia e Cartografia, 2002. Escala 1:70.000.

BRASIL. Ministério do Exército. Diretoria do Serviço Geográfico. $1^{\text {a }}$ Divisão de Levantamento. Cartas topográficas de Formosa, São Domingos, Pinhalzinho, Xaxim. Porto Alegre: 1978. Escala 1:50.000. 
CARRARO, F. Geografia de Santa Catarina. São Paulo: FTD, 2004, 142 p.

CONSELHO NACIONAL DO MEIO AMBIENTE - CONAMA. Resolução nº 237, de 19 de dezembro de 1997. Ministério do Meio Ambiente, Brasília, DF, 1997.

CHRIST, P. O. Avaliação da capacidade hídrica do deflúvio da bacia do Rio Quilombo. Monografia de especialização. CEFET, Pato Branco, 2003.

EMPRESA DE PESQUISA AGROPECUÁRIA E EXTENSÃO RURAL DE SANTA CATARINA S. A. - EPAGRI. Estação pluviométrica. Gerência Regional de Chapecó, SC, 2005.

HOUAISS, A. Dicionário Houaiss da língua portuguesa. São Paulo: Objetiva, 2001.

INSTITUTO BRASILEIRO DE GEOGRAFIA E ESTATÍSTICA - IBGE. Censo demográfico de Santa Catarina. Rio de Janeiro, 2000.

LIMA, W. P. Hidrologia de matas ciliares. São Paulo: EDUSP, 1996.

PELUSO JUNIOR, V. A. Aspectos geográficos de Santa Catarina. Florianópolis: FCC/UFSC, 1991. 284 p.

PERTILE, N. Marcas da "integração" na agricultura familiar de Quilombo, SC. 190 p. Dissertação (Mestrado em Geografia) - Programa de Pós-Graduação em Geografia, Universidade Federal de Santa Catarina, Florianópolis. 2001.

SANTA CATARINA. Secretaria de Estado do Desenvolvimento Urbano e Meio Ambiente. Bacias hidrográficas de Santa Catarina: diagnóstico geral. Florianópolis: 1997. $163 \mathrm{p}$.

SEGANFREDO, M. A. A poluição por dejetos de suínos, o aspecto econômico e o direito público. Revista Pork World, São Paulo, n. 9, ano 2, p. 42 - 44, 2002.

TESTA, V.W.; ESPÍRITO SANTO, F.R.C. Principais solos do oeste catarinense: aspectos gerais para identificação a campo e suas principais limitações ao uso agrícola. Florianópolis: EPAGRI, 1992, 75 p. (EPAGRI, Boletim Técnico 60).

VOTTO, A. G. Zoneamento da poluição hídrica causada por dejetos suínos no extremo oeste de Santa Catarina. 201 p. Dissertação (Mestrado em Geografia) Programa de Pós-Graduação em Geografia, Universidade Federal de Santa Catarina, Florianópolis. 1999.

\section{DOCUMENTOS EM MEIO ELETRÔNICO}

ASSOCIAÇÃO BRASILEIRA DE CRIADORES DE SUÍNOS - ABCS. Dados gerais. Disponível em $<$ http:www.abcs.com.br $>$. Acesso em: 20 out. 2004.

ASSOCIAÇÃO CATARINENSE DE CRIADORES DE SUÍNOS - ACCS. Relatório Anual 2004. Disponível em: <http://www.accs.org.br/Relatorio\%202004.doc $>$. Acesso em: 05 nov. 2005. 
COMPANHIA DE TECNOLOGIA DE SANEAMENTO AMBIENTAL - CETESB. Índice de qualidade das águas. Disponível em $<\mathrm{http}$ ://www.cetesb.sp.gov.br/Agua/rios/variaveis.asp/>. Acesso em: 01. jun. 2005.

DEPARTAMENTO AUTÔNOMO DE ÁGUA E ESGOTOS - DAAE. O Aqüífero

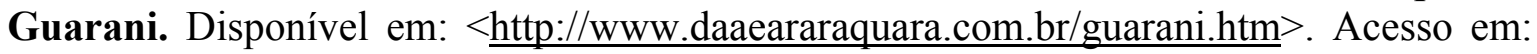
25 jan. 2006.

EMPRESA BRASILEIRA DE PESQUISA AGROPECUÁRIA - EMBRAPA. Sistema Brasileiro de Classificação de Solos. Disponível em: $<$ http://www.cnps.embrapa.br/search/novids/oqvai8/oqvai8.html $>$. Acesso em: $28 \mathrm{dez}$. 2005 .

EMPRESA DE PESQUISA AGROPECUÁRIA E EXTENSÃO RURAL DE SANTA CATARINA S. A. - EPAGRI. Aspectos gerais. Disponível em $<$ http://www.epagri.rctsc.br>. Acesso em: 10 mai. 2005.

INSTITUTO BRASILEIRO DE GEOGRAFIA E ESTATÍSTICA - IBGE. Cidades Santa Catarina. Disponível em: $<$ http://www.ibge.gov.br/cidadesat/default.php $>$. Acesso em: 18 nov. 2005.

SECRETARIA DE ESTADO DA RECEITA. Disponível em: $<$ http://www.receita.rj.gov.br/sub_adj_rec/sear/valor_ufirrj.shtml $>$. Acesso em: $03 \mathrm{dez}$. 2005.

SISTEMA INTEGRADO DE MONITORAMENTO AMBIENTAL DA BACIA DO RIO

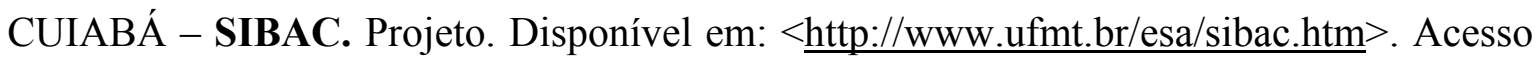
em: 27 dez. 2005. 